\title{
Nevirapine Hepatotoxicity: Implications of Risk Factors
}

\author{
${ }^{1}$ Elias Adikwu, ${ }^{2}$ Oputiri Deo, \\ ${ }^{2}$ Oru-Bo Precious Geoffrey and ${ }^{2} D$. Akuegbe Enimeya \\ ${ }^{1}$ Department of Pharmacology, Faculty of Basic Medical Sciences, \\ College of Health Sciences, University of Port Harcourt, Choba, Rivers State, Nigeria \\ ${ }^{2}$ Department of Pharm Tech, College of Heath Technology, Otuogidi, Ogbia Bayelsa State, Nigeria
}

Received 2013-02-09, Revised 2013-05-15; Accepted 2013-06-03

\begin{abstract}
Highly active antiretroviral therapy is used in the management of HIV/AIDS; it has contributed tremendously in the reduction of mortality and morbidity rate in HIV patients. Despite the outstanding achievement with the use of HAART its major limitation is toxicity. Among these toxicities is hepatotoxicity which is said to be associated with nevirapine containing highly active antiretroviral therapy. Recent reports have attributed nevirapine hepatotoxicity to some risk factors which includes genetic, gender, CD4 cell count, hepatitis and pregnancy in HIV patients which is of clinical concern. Available information on nevirapine hepatotoxicity and reported risk factors associated with nevirapine hepatotoxicity was collected and evaluated. In the light of available literature hepatitis B or C is observed to be a risk factor in HIV patients taking nevirapine containing regimens. Hepatitis $\mathrm{B}$ and or $\mathrm{C} / \mathrm{HIV}$ co infection contribute to the progression of hepatotoxicity in HIV patients taking nevirapine containing regimens. The Human Lymphocyte Antigen (HLA) is the genetic element that is reported to drive nevirapine hepatotoxicity, but available information is sketchy to substantiate the involvement of HLA hence further evaluation is required. Pregnancy, Gender and CD4 cell count might not be risk factors in nevirapine hepatotoxicity but available body of knowledge showed discrepancies in reports which may warrant further evaluation. In this review no correlation was found between pregnancy, CD4 cell count and gender with respect to nevirapine associated hepatotoxicity but this leaves a space for further evaluation. Nevirapine should not be administered to HIV positive patients with hepatitis co infection except benefits out weights risk. When administered routine monitoring of liver function should be an objective.
\end{abstract}

Keywords: Nevirapine, Hepatotoxicity, Risk Factors

\section{INTRODUCTION}

Highly Active Antiretroviral Therapy (HAART) is used for the management of HIV infected patients. Antiretroviral therapies hamper the growth of the HIV virus, thereby causing the suppression of viral particle multiplication and eventually leading to decreased viral load, thereby prolonging the patient's life span. HAART has contributed tremendously in the reduction of mortality and morbidity associated with HIV infection. Despite the outstanding achievement with the use of
HAART there are some drawbacks associated with HAART. Reports have associated HAART with lots of toxicities e.g., lactic acidosis (Carr and Coper, 2000) nephrotoxicity (Herlitz et al., 2010) hepatotoxicity (Prakash et al., 2001), Stephen johnsons syndrome (Fagot et al., 2001), lipodystrophy (Saint-Marc et al., 1999), dislipidemia (Friis-Moller et al., 2003a) hyperglycemia (Friis-Moller et al., 2003b). These toxicities have led to impaired compliance, therapy discontinuation, therapy modification and even death (Bonnet et al., 2002; Lyons et al., 2006; Manfredi and Corresponding Author: Elias Adikwu, Department of Pharmacology, Faculty of Basic Medical Sciences, College of Health Sciences, University of Port Harcourt, Choba, Rivers State, Nigeria Tel: $+2347068568868,+2348128209442$ 
Calza, 2006). Of resent toxicities associated with nevirapine containing HAART have drawn lots of clinical attention. Nevirapine is the first dipyridozepinone Nonnucleoside Reverse Transcriptase Inhibitor (NNRTI) approved for use in HIV-infected patients. Its efficacy has been well demonstrated in numerous clinical trials. It has activity against HIV-1 but does not have significant activity against HIV-2 or other retroviruses (Harris and Montainer, 2000). Nevirapine mechanism of action involves binding directly to HIV-1 reverse transcriptase enzyme and causing a structural change that disrupts the formation of the active site and leads to impaired polymerization activity (Murphy and Montaner, 1996). Clinically Nevirapine is typically used as a component of highly active antiretroviral regimen. In addition nevirapine has been used in the prevention of mother to child transmission of HIV. Nevirapine containing highly active antiretroviral therapy is associated with some toxicological effects; of these toxicological effects is hepatotoxicity which has been widely reported and has drawn lots of concern.

Animal studies and case reports have attested to nevirapine hepatotoxicity (Adaramoye et al., 2012; Adewale et al., 2012; Pilliero and Purdy, 2001). Cohort and other studies, have reported various grades, 1, 2, 3 and 4, of hepatotoxicity due to nevirapine (Lyons et al., 2006; McKoy et al., 2009) and in some cases deaths were reported (Bera and Naidoo, 2012).

Reports by some authors have correlated nevirapine hepatotoxicity with some risk factors. Highlighted risk factors include genetic predisposition (Martin et al., 2005), CD4 cell count (Stern et al., 2003), gender (Lazzari et al., 2008), co-infection with hepatitis B or C (Mbougua et al., 2010) and even pregnancy (Aaron et al., 2010). Some of these risk factors have led to nevirapine therapy modification in W H O treatment guidelines for HIV patients. Due to discrepancies in reports with respect to these risk factors this second part of our work reviewed available literature on reported risk factors associated nevirapine hepatotoxicity and their clinical implication.

\subsection{Nevirapine Hepatotoxicity and Risk Factors}

Nevirapine hepatotoxicity is of great clinical concern. This has led to our previous work on concentrationeffect, incidence and mechanisms of nevirapine hepatotoxicity. We systematically reviewed case reports on hepatotoxicity associated with nevirapine containing highly active antiretroviral therapy. In some case reports nevirapine hepatotoxicity manifested as hepatitis, jaundice, hepatic failure and hepatic necrosis (Bera et al.,
2012; Hitti et al., 2004), Experimental animal studies have also shown that nevirapine hepatotoxicity is associated with elevation of liver enzymes and other biomarkers of liver function (Umar et al., 2008). Nevirapine hepatotoxicity is reported to be associated with some risk factors which have lead to nevirapine therapy modification. But there are discrepancies in reports with respect to these risk factors. This has warranted calls from some quarters for a re-evaluation of some of these risk factors and modifications which might have prevented some HIV patients from deriving maximum benefits from nevirapine containing highly active antiretroviral therapy. Some of these risk factors are discuss below.

\subsection{Gender and CD4 Cell Count}

Concern has been raised on CD4 cell count and gender as risk factors in nevirapine hepatotoxicity. One of the warnings about the use of nevirapine by its Manufacture Boehringer Ingelhein is increase risk of toxicity base on CD4 cell count and gender (Knobel et al., 2004). Boehringer Ingelhein database reported that the risk of symptomatic hepatotoxicity was 12 times greater in women with CD4cell count $>250$ cell $\mu \mathrm{L}^{-1}$ in comparison with women with CD4 count $<250$ cell $\mu \mathrm{L}^{-1}$ (Stern et al., 2003). This has made The US Food and Drug Administration and the European Medicines Agency warned on the increased risk of hepatotoxicity in antiretroviral-nave patients with higher CD4 cell counts ( $>250$ cells $\mu \mathrm{L}^{-1}$ in women and $>400$ cell $\mu \mathrm{L}^{-1}$ in men (Antela et al., 2010). This has instigated us to review relevant literature for correlation between CD4 cell count, gender and nevirapine hepatotoxicity. There are fundamental studies that have shown correlation between CD4 cell counts, gender and nevirapine hepatotoxicity. Among these studies is the report of Jamisse et al. (2007). Jamisse et al. (2007) showed that severe hepatotoxicity associated with nevirapine therapy was observed to be common at high CD4 cell count. Similar observation was reported by Joao et al. (2006). He and colleagues were able to show that CD4 cell count $>600$ cell $\mu \mathrm{L}^{-1}$ is a risk factor for nevirapine toxicity. This can be further supported by the sub analyses of the $2 \mathrm{NN}$ study. The $2 \mathrm{NN}$ study was a randomized, controlled trial comparing efficacy between regimens containing nevirapine, efavirenz in addition to stavudine and lamivudine in antiretroviral-naïve HIV-I-infected patients (Leth et al., 2005; Storfer et al., 2005). In the Euro SIDA cohort study in which the risk of nevirapine 
discontinuation in relation to high and low CD4 cell counts was investigated, it was observed that patients with high CD4 cell count had increased risk of discontinuation compared with patients with low CD4 cell count and the risk was higher in naïve patients (Mocroft et al., 2007). An analysis of 905 HIV positive patients receiving nevirapine containing regimens was conducted by Torty et al. (2007). Toti and co researchers observed that elevation in transaminases in patients prescribed nevirapine containing regimens could be attributed to Gender and CD4+ T-cell count.

There are many reports by some authors that are at variance with the reported relationship between nevirapine hepatotoxicity, gender and CD4 cell counts. One of these reports is the TOSCANA study. This study evaluated the relationship between CD4 cell counts and liver toxicity in patients undergoing treatment simplification or substitution with nevirapine. These authors, after assessing 221 patients (64 males and 57 females), showed that nevirapine hepatotoxicity is not associated with CD4 cell count. The rate of hepatotoxicity was higher in patients with low CD4 cell count compared to patients with high CD4 cell count but it was not statistically significant (Leth et al., 2005). Furthermore, no relationship between hepatoxicity and gender-stratified CD4 cell counts was noted in a metaanalysis. This study involved 40 patients, including virologically suppressed patients switching to nevirapine containing antiretroviral therapy (Lazzari et al., 2008). German researches reported incidence of liver toxicity in a retrospective study which included 507 patients, they observed that gender and CD4 cell counts were not significantly associated with increased risk of hepatotoxicity (Wolf et al., 2006). The above study is in agreement with the work of Knobel et al. (2004). He and co researchers performed a retrospective study involving 142 patients. They reported that the recommendation inhibiting the use nevirapine in drug-naïve patients due to toxicity on the basis of gender and CD4 cell count do not seem to be of use in preventing the occurrence of side effects associated with the use of nevirapine.

In another study that included 346 patients starting nevirapine based therapy (41 naïve and 314 experience patients), only $5.8 \%$ of patients interrupted therapy because of hepatotoxicity and neither female gender nor CD4 cell count $>250$ cells $\mu \mathrm{L}^{-1}$ was a risk factor for this adverse event (Manfredi and Calza, 2006). In a study conducted in British Columbia which included 685 antiretroviral-naïve patients starting nevirapine, $9.6 \%$ of patients met the definition for hypersensitivity reaction and no variables were identified as risk factors except co-infection with HCV (Phillips et al., 2007). Nevirapine induced hepatotoxicity in HIV infected pregnant Kenyan women who initiated triple antiretroviral therapy at 34 weeks gestation was evaluated by Peter et al. (2011). He and coworkers concluded that nevirapine use but not CD4 count $>250$ cells $/ \mathrm{mm}^{3}$ was associated with hepatotoxicity. Other studies have found that hepatic adverse events with systemic symptoms were 3.2-fold more common in men (Baylor and Johann-Liang, 2004; Stern et al., 2003).

Medrano et al. (2008) in their work "risk for immune-mediated liver reactions by nevirapine" highlighted on the change of the modification of the product label of nevirapine due to reports on hepatotoxicity of nevirapine particularly when initiated in women with CD4 cell count $>250$ cells $/ \mathrm{mm}^{3}$. They further reported that due to available data on virological suppressed patients who switch to nevirapine as part of their simplification strategy, regardless of their current $\mathrm{CD} 4$ cell count, patients on simplification strategy did not show increase risk of hepatotoxicity with elevated CD4 count. In a pooledmeta analysis involving 410 patients, 133 patients had low CD4 counts (women $<250$ cells $\mu \mathrm{L}^{-1}$ and men $<400$ cell $\mu \mathrm{L}^{-1}$ ). Two hundred and seventy seven patients were categorized as high CD4 counts. No significant difference was observed in those groups with respected to $\mathrm{CD} 4$, age, sex or $\mathrm{HCV}$ co-infection rates. Within the first 3 months after switching to nevirapine, 3 patients $(2 \%)$ in the low CD4 count group developed hepatotoxicity while in the high CD4 group only 12 patients $(4 \%)$ developed hepatotoxicity. Using a meta-regression model none of the variables shared significant correlation with increase risks of hepatotoxicity using nevirapine in simplification strategy.

A retrospective cohort study of 910 patients $(57 \%$ males) of nave HIV-infected patients on nevirapine base HAART with CD $<250$ cells $\mu \mathrm{L}^{-1}$ was performed by Manosuthi et al. (2007). Incidence of clinical hepatitis was 2 per 1,000 people-months, probabilities of hepatitis at $1,2,3$ and 6 months after HAART were 0.5, 0.7, 0.8 and $1.1 \%$ respectively. It was observed that incidence of nevirapine associated severe hepatitis that led to nevirapine discontinuation among HIV infected patients with baseline CD4 $<250$ cells $\mu \mathrm{L}^{-1}$ was low (Manosuthi et al., 2007).

Coffie et al. (2010) were able to show lack of correlation between CD4 cell count $>250$ cells $/ \mathrm{mm}^{3}$ and nevirapine containing HAART induce hepatotoxicity. In their work, 290 women on nevirapine containing HAART with a median CD4 count of $186 \mathrm{cell} / \mathrm{mm}^{3}$ were used. They reported that at 24 months, the probability of occurrence of 
hepatotoxicity was not different between women with a CD4 cell count $>250$ cells $/ \mathrm{mm}^{3}$ and women with a CD4 count $<250$ cells $/ \mathrm{MM}^{3}(8.3 \%$ Vs $9.9 \%$ log-rank test: $\mathrm{p}=$ 0.75) (Coffie et al., 2010).

\subsection{Hepatitis $B$ and $C$}

Co infection with Hepatitis B Virus (HBV) or Hepatitis C Virus (HCV) in HIV infected patients receiving HAART containing nevirapine is of clinical concern due to reported incidences of hepatotoxicity. The risk of hepatotoxicity is reported to increase in HIV patients co-infected with HBV or HCV taking nevirapine containing regimens (Stern et al., 2003; Almond et al., 2004a; 2004b). HCV and HIV co-infection have been reported to increase the risk of HAART associated hepatotoxicity 2 to 10 fold compared with HIV mono infection (Bonacini, 2004; Sulkowski et al., 2002). World Health Organization recommends the use of nevirapine with caution and regular monitoring in patients who have baseline grade 1, 2 or 3 elevations of liver enzymes, positive or unknown $\mathrm{HBV}$ and $\mathrm{HCV}$ testing (WHO). There are quite a number of researches that attested to $\mathrm{HBV}$ and $\mathrm{HCV}$ as risk factors in nevirapine hepatotoxicity. One of these researches was performed in Thailand. Six hundred and ninety two (692) patients were used and all received at least two Nucleoside Reverse Transcriptase Inhibitors. Two hundred and fifteen (215) patients also received a Non Nucleoside Reverse Transcriptase Inhibitor (NNRTI) and three hundred and fifteen (315) received protease inhibitors. In this study, severe hepatotoxicity was defined as an increase in alanine amino transferase level five times the upper limit of normal and an increase of at least-100 u I ${ }^{-1}$ from baseline. Liver function tests were available at baseline and in weeks 4, 8, 12, 24, 36 and 48. Hepatitis $B$ virus and Hepatitis $C$ virus testing was performed on stored serum. Incidence of severe hepatotoxicity was $6.1 / 100$ person-years. In multivariate analysis prediction of severe hepatotoxicity were HBV or HCV co-infection and NNRTI containing therapy. Incidence of severe hepatotoxicity was particularly high among patients receiving nevirapine (18.5/100 personyears: 95\% CI, 11.6-27.8) (Law et al., 2003). A prospective study of 568 patients, primarily Caucasians and African Americans, also demonstrated a higher risk of severe hepatotoxicity among patients with chronic viral hepatitis $\mathrm{C}$ or $\mathrm{B}$ infections. However, such risk was remarkably reduced by concurrent interferon-based therapy with sustained $\mathrm{HCV}$ clearance in patients with HIV/HCV coinfection. This study showed that Chinese HIV+ patients with high HCV RNA levels had a significantly greater risk of severe liver toxicity than those patients with low HCV RNA levels (Labarga et al., 2007). Similar observation was reported by some authors (Fuping et al., 2010).

In an attempt to describe the spectrum of liver disease in HIV patients attending HIV clinic in Kampala, Uganda, 77 patients were selected and investigated among patients who presented Jaundice, right upper guardant pain with fever or malaise ascites and /or tender hepatotoxicity. Among other observations, Hepatitis B surface antigen was positive in $11(15 \%)$ of the patients. Hepatitis B or C infection were reported to be one of the probable etiology in 60 (78\%) of the 77 patients with HIV infection who presented symptoms/or signs of liver disease (Ocama et al., 2008).

In a research with the objective of investigating the relationship between the use of different antiretroviral drugs and liver fibrosis in patients with HIV and HCV co infections, $152 \mathrm{HIV} / \mathrm{HCV}$ co-infected patients were evaluated. These patients have available liver biopsy sample and estimated duration of $\mathrm{HCV}$ infection. It was observed that patients who were administered nevirapine base HAART showed progression in liver fibrosis (Macias et al., 2004). A study involving 152 patients co-infected with HIV and HCV was performed by Pineda and Macias (2005). They reported that $31 \%$ of patients administered protease inhibitor had fibrosis $\mathrm{f3}$ and $\mathrm{f4}$. Therapy with protease inhibitor was associated with lower fibrosis progression rate when compared with nevirapine. It was also observed that more patients among nevirapine recipients than among nevirapine naive individuals showed advance liver fibrosis (56\% versus $36 \% \mathrm{p}=0.04)$. The prevalence of advance fibrosis was greater in patients exposed to nevirapine for longer than 1 year. The levels of alanine aminotransferase increased 2.5 -fold from baseline in $76 \%$ individual who received nevirapine (Pineda and Macias, 2005).

The above reports are at variance with an analysis on the effect of exposure to Non Nucleoside ReverseTranscriptase Inhibitors (NNRTIs) and Protease Inhibitors (PIs) on the progression of liver fibrosis in patients with human immunodeficiency virus and hepatitis $\mathrm{C}$ virus co-infection performed by Berenguer et al. (2008). $\mathrm{He}$ and colleagues evaluated data of liver biopsy from 201 co-infected patients. Multinomial logistic regression analysis and the fibrosis progression rate were used to assess the association between cumulative exposure to antiretroviral drugs and stage fibrosis. In contrast to other studies it was observed that exposure to nevirapine was more consistently associated with a reduction in fibrosis progression than exposure to efavirenz. 
In a study that assessed the incidence of hepatotoxicity in adult patients co-infected with HIV/HCV in two out patients' infectious disease clinics, 544 patients were evaluated. The incidence of severe hepatotoxicity was $10.7 \% \quad(6 / 56$ patients). Severe hepatotoxicity occurred in only one patient who was administered nevirapine. These researchers concluded that incidence of severe hepatotoxicity appears to be low in $\mathrm{HIV} / \mathrm{HCV}$ co-infected patients receiving a $\mathrm{P} 1$ and or NNRTIs-base regimen (Heil et al., 2010).

Sulkowski et al. (2002) carried out a prospective study which evaluated the incidence of severe hepatotoxicity (grade 3 or 4 change in ALT and AST levels) in 568 patients receiving NNRT1s- containing antiretroviral therapy. Three hundred and twelve (312) participants were prescribed efavirenz while 256 received nevirapine. Hepatitis $\mathrm{C}$ Virus (HCV) and Hepatitis B Virus (HBV) were detected in $43 \%$ and $7.7 \%$ of patients respectively. Severe hepatotoxicity was observed in $15.6 \%$ of patients prescribed nevirapine and $8.0 \%$ of patients prescribed efavirenz. Severe hepatotoxicity occured throughout the course of NNRT1 therapy and was more prevalent in patients taking nevirapine and that are co infected with HCV or HBV.

Mbougua et al. (2010) conducted a retrospective cohort involving 169 HIV infected patients who enrolled from 2001 to 2003 in two major hospitals. All patients received nevirapine and lamivudine plus stavudine or zidovudine, of the 169 HIV patients 35 (21\%) were coinfected with hepatitis, hepatitis C (14) and hepatitis B (21). Among other observations, using multivariate analyses, the risk of hepatotoxicity was 2 -fold in co infected patients. It was suggested that testing for HBV and HCV should be systemically performed before initiating antiretroviral therapy. Transaminases elevations at baseline or during treatment should be a decisive argument for testing when hepatitis state is known (Mbougua et al., 2010). An evaluation of patients in an antiviral therapy unit of a reference centre in northern Italy with median age 38.9 year was performed by Maggiolo and colleagues. One hundred and sixty four (28\%) were females while 321 subjects $(55.2 \%)$ were coinfected with hepatitis $\mathrm{C}$ virus but none of them had previously received $\mathrm{HCV}$ therapy. These patients received 744 nevirapine-based regimens. Among other observations hepatotoxicity was the cause of treatment discontinuation in $29(3.9 \%)$ cases with most incidences (20,3.4\%) involving a grade 4 liver function test alteration. Elevated serum ALT (levels $>$ grade 3 ) were observed in $10.2 \%$ of patients treated with nevirapinebased regimens, reflecting an overall incidence rate of
5.3 cases per 100 person-years. They were able to conclude that nevirapine should be used with caution in patients co-infected with hepatitis $\mathrm{C}$ virus or with elevated liver function test (Magiolo et al., 2007).

The work of Wang et al. (2011) also showed that HCV is a risk factor in nevirapine associated hepatotoxicity in HIV patients. They evaluated virologic response and hepatotoxicity in Chinese patients with HIV infection. In this study a total of $227 \mathrm{HIV}$-infected patients were evaluated, of which 173 patients were treated with nevirapine containing antiretroviral regimens for at least 24 weeks. One hundred and ninety one patients were evaluated for liver toxicity. The incidence of liver toxicity was $71 \%(136 / 191)$ including 43 patients $(23 \%)$ with severe liver toxicity within 12 weeks of starting therapy. Their data confirmed that hepatitis $\mathrm{C}$ virus co-infection was significantly associated with an increase risk of severe liver toxicity in Chinese HIV patients (Wang et al., 2011).

Furthermore, Bonnet et al. (2002) performed a retrospective study to evaluate, under routine circumstances, tolerance and immunovirological changes associated with nevirapine containing antiretroviral therapy of which 137 patients were evaluated. During a follow-up period for two months, $33 \%$ of patients presented side effects associated with nevirapine and 21 discontinued treatment because of poor tolerance. The percentage of patients with $\mathrm{HCV}$ and/ or $\mathrm{HBV}$ co infection who had increased alanine aminotransferase levels $>100 \mathrm{IU} \mathrm{L}^{-1}$ increased from $19.4 \%$ at baseline to $42.9 \%$. They found out that co-infection with HCV or HBV increased the risk of hepatotoxicity. Despite the fact that reports correlated hepatitis B or C as risk factors Vogel et al. (2009) reported that HCV did not impair the pharmacokinetics parameters of nevirapine in HIV patients. They buttress their points by performing a $12 \mathrm{~h}$ pharmacokinetics analysis in 18 patients. Seven patients had HIV and HCV co-infection and two patients are HIV mono infected. This analysis was performed in order to establish the differences in nevirapine metabolism in HIV/HCV co-infected and HIV mono infected patients. Comparatively, their data showed that HIV/HCV coinfection does not alter the pharmacokinetics of nevirapine in patients with preserved liver function. One of the limitations in this study is the sample size which could make the probability of this result occurring by chance (Vogel et al., 2009).

\subsection{Pregnancy}

HIV infection is known to be associated with some clinical symptoms which are always compounded by 
the presence of opportunistic infections as seen in WHO HIV clinical stages. Studies have shown that HIV infection could be associated with elevated levels of ALT, recently elevated levels of ALT $>40 \mathrm{IU} \mathrm{L}^{-1}$ were reported (Nagu et al., 2012; Peters et al., 2010). Similar observation was also reported by some scholars (Dieterich et al., 2004; Ofotokun et al., 2007; Coca et al., 2010). In Europe and North America prevalence of elevated ALT in HIV patients was reported to vary between 19 and 29\% (Weidle et al., 2008). It was further shown that elevated levels of ALT in HIV patients is gender sensitive, it is higher in males than females (Weidle et al., 2008; Nagu et al., 2012).

It has also been reported that hepatic disease complicates nearly $3 \%$ of all pregnancies and is a significant cause of morbidity during the gravid state. However, several disease syndromes like acute fatty liver, acute cholestasis, ruptured and liver hematoma can occur during pregnancy (Chng et al., 2002). Pregnancy could be associated with alterations in the results of standard liver tests e.g., alkaline phosphatase raises modestly in the third trimester (Bacq et al., 1996). These reports above supported that HIV infection, nevirapine therapy and pregnancy could be associated with hepatic events. The question is "could pregnancy in HIV patients be a risk factor in nevirapine hepatotoxicity". In the light of this question and due to discrepancies in reports, in this aspect we evaluated available literature to examine the correlation between pregnancy and nevirapine hepatotoxicity. One of these reports that contradict the use of nevirapine in pregnancy is the work of Bera and Mia (2012) who evaluated 14 studies with 2663 participants. Adverse nevirapine related events among Art-naïve pregnant women at CD4 250 cell $\mu \mathrm{L}^{-1}$ who commenced therapy at higher versus lower CD4 counts were evaluated. They observed that initiating nevirapine base ART in pregnant women especially at CD4 $>250$ cells $\mu \mathrm{L}^{-1}$ increased toxicity risk and should be avoided and necessitating urgent revision of current guidelines supporting this practice. Clinical report showed four reported cases of fulminant hepatitis culminating in maternal death associated with nevirapine as part of combination antiretroviral therapy in pregnancy (Hitti et al., 2004; Langlet et al., 2000; Lyons et al., 2006).

Bera et al. (2012) also reported two case of maternal death following nevirapine containing antiretroviral therapy. These patients have CD4 cell count of 119 and 201 cells microl $^{-1}$ which is $<250$ as stipulated by the manufacturers of nevirapine. These cases were associated with nevirapine induced hepatotoxicity (liver failure) characterized by elevated levels of liver enzymes.
To evaluate the maternal tolerability of nevirapine as part of highly active antiretroviral therapy in pregnancy, a retrospective study was carried out by Lyons et al. (2006). One hundred and twenty three (123) women initiated nevirapine as part of combination antiretroviral therapy. Eight women which is equivalent to (9.4\%) developed grade 3 or 4 hepatotoxicity, including two women who died from fulminant hepatitis. Fourteen (16.4\%) developed grade 2 hepatotoxicity, seven (8.2\%) developed grade 1 hepatotoxicity. Women who experienced more severe hepatotoxicity had higher pretreatment CD4 counts (p 50.01).

The Pediatric AIDS Clinical Trials Group Protocol 1022, randomized 38 antiretroviral-naive pregnant women at 10-30 weeks' gestation who were administered nelfinavir or nevirapine with zidovudine plus lamivudine. Toxicity was seen in $(5 \%)$ of 21 subjects administered nelfinavir and (29\%) of 17 subjects who were administered nevirapine $(\mathrm{p}=0.07)$. Within the nevirapine administered group, 1 subject developed fulminant hepatic failure and died. All nevirapine toxicity were observed among subjects with a CD4 cell count $>250$ cells microL $^{-1}$. Continuous nevirapine therapy may be associated with increased toxicity among HIV-1-infected pregnant women with CD4 cell counts $>250$ cells microL ${ }^{-1}$ (Hitti et al., 2004).

In a retrospective cohort study, the risk of hepatotoxicity in HIV-1 positive pregnant and nonpregnant women starting combined ART was evaluated. Four-hundred and twenty-five pregnant and 1121 nonpregnant women were used in this study. Results showed that the presence of hepatitis $\mathrm{C}$ virus could be Independent risk factor of hepatotoxicity in women and nevirapine use (Snijdewind et al., 2012). In a subsequent prospective study performed in Mozambique, it was reported that incidence of severe hepatoxicity was seen only in pregnant women with baseline CD4 cell counts $>250$. In this study 146 pregnant women were put on a nevirapine-based regimen, about $46 \%$ of whom had CD4 cell counts between 250-350 cells microl ${ }^{-1}$. Grade I-IV toxicity involving the skin or liver was observed in $39 \%$ of participants, with only $6 \%$ needing to switch regimens. Seven which correspond to $5 \%$ had grade II hepatotoxicity and four ( $3 \%$ ) had severe (grade III or IV) hepatotoxicity. The rate of severe liver toxicity in women with baseline CD4 cell counts between 250-350 cells microl ${ }^{-1}$ was $6 \%(p=0.02)$. A greater proportion of women with higher CD4 cells also developed SJS which is not statistical significance (Jamisse et al., 2007). Kondo et al. (2008) He and colleagues evaluated 170 women who initiated nevirapine during pregnancy, but 
only 133 were included in this study. Twenty-seven women $(20.3 \%)$ presented adverse effects and liver function abnormalities accounted for $22.2 \%(6 / 27)$ of the cases. All nevirapine side effects were developed in less than seven weeks. All patients who experienced hepatotoxicity had pretreatment CD4 counts $>$ or $=250$ cells microL $^{-1}$. Most of the adverse events were cutaneous events, but all six $(5.5 \%)$ who experienced hepatotoxicity had pretreatment CD4 counts $>250$ cells $\mu \mathrm{L}^{-1}$. Only two were grade III and did not become symptomatic. Nevirapine was discontinued in all women with grade II/III liver toxicity (Kondo et al., 2007).

A retrospective study of all pregnant women prescribed nevirapine was performed. In this study one hundred and fifty-seven women were used. Thirty-one $(19.7 \%)$ presented cutaneous and/or hepatic toxicity and liver function abnormalities were noted in $22.6 \%$ of women. Grade 1, 2 and 3 hepatotoxicity was observed in $0.6,2.5$ and $1.3 \%$ women respectively. Median absolute CD4 cell counts were 465.4 and 416.6 cells microL ${ }^{-1}$ in women with and without side effects, respectively $(\mathrm{p}=$ 0.3). Patients who manifested hepatotoxicity had pretreatment CD4 counts $>250$ cells microL $^{-1}$. There was no association between high CD4 counts and adverse events with respect to cutaneous and hepatic reactions; nevertheless, hepatotoxicity occurred only in pregnant women with CD4 counts $>250$ cells microL ${ }^{-1}$ (Kondo et al., 2008). Toxicity data of 8216 patients treated with nevirapine-containing regimens were reviewed by McKoy et al. (2009). Among 4740 HIV-infected pregnant women, 3031 received short course of nevirapine therapy while 1709 received long course of nevirapine therapy. Nevirapine, rates of grade 1-2 hepatotoxicity were $0.62 \%$ and $7.04 \%$, respectively and rates of grade 3-4 hepatotoxicity were $0.23 \%$ versus $4.39 \%$, respectively $(\mathrm{p}<0.001)$ for both . Therapy duration appears to significantly predict nevirapine hepatotoxicity. Short course nevirapine for HIV prophylaxis is associated with fewer hepatotoxic reactions for pregnant HIVinfected women (McKoy et al., 2009).

These researches above were able to establish some degree of correlation between pregnancy, CD4 cell count and nevirapine hepatotoxicity. Nevertheless there are also some researches that couldn't establish any correlation between nevirapine hepatotoxicity and pregnancy. One of these reports is the work of Marazzi et al. (2006) who carried out analysis of clinical files of $703 \mathrm{HIV}$ positive pregnant women treated with nevirapine-containing regimen between May 2002 and July 2004. The women were on nevirapine containing regimen for a median of 127 days, starting on average at the 27 th week of gestation and continue up to a maximum of 6 months after delivery. After 2 months of therapy $78.6 \%$ of patients had viral load $<1000 \mathrm{HIV}-\mathrm{I}$ RNA copies $/ \mathrm{ml}$, average CD4 cell increased from 490 cells $\mu \mathrm{L}^{-1}$ to 630 after therapies. Incidence of hepatotoxicity was $6.5 \%$. In this study they observed that nevirapine-containing regimens are safe in pregnant women at all CD4 cell count in African settings.

Black and Rees (2008) carried out a retrospective analysis of pregnant women on nevirapine-based highly active antiretroviral therapy. Three hundred and ninety women of Median age 29 and median pre-treatment CD4 cell counts of 157 cells $\mu \mathrm{L}^{-1}$ were evaluated. Their observations include elevation of baseline Alanine Transaminase (ALT) in $2.8 \%$ of women which represents $(11 / 390)$ while three of these patients which represents $(0.8 \%, 3 / 390)$ developed clinical hepatitis with jaundice. They inferred that in pregnant women, nevirapinecontaining ART has a favorable safety profile, with a low incidence of serious hepatic events.

Forty-six pregnant women containing $85 \%$ of black Africans were administered nevirapine containing antiretroviral regimen during pregnancy, only two showed hepatic adverse events. This may suggest that pregnancy may not be a risk factor in nevirapine induced hepatotoxicity (Edwards et al., 2001a; 2001b). In a retrospective cohort study for the evaluation of nevirapine toxicity in pregnant women 161 women were exposed to nevirapine for $>7$ days. It was observed that no serious liver toxicity occurred except for one grade 4 cholestasis. This added credence to low hepatic events with nevirapine in pregnancy (Joao et al., 2006). In a study to evaluate nevirapine tolerability in HIVinfected pregnancy women, 125 women received nevirapine. Majority of the women were hispanic and $36(29 \%)$ black, it was observed that nevirapine was tolerated in pregnancy with less hepatotoxic effect (Kramer et al., 2004). Similar observation was reported by (Bershoft-Matcha et al., 2004). Adverse events due to antiretroviral therapy initiation were retrospectively assessed in a multi-site cohort of 612 women, 152 $(24.8 \%)$ initiated nevirapine-based regimens with 86 (56.6\%) pregnant; $460(75.2 \%)$ initiated non-nevirapine regimens with $67(14.6 \%)$ pregnant. Among other parameters, predictors of liver enzyme elevation were determined using univariate and multivariate analyses. No significant difference was found between regimens in the development of new grade $\geq 2$ liver enzyme elevation $(p=0.885)$. Multivariate logistic regression demonstrated an increased likelihood of liver enzyme elevation with HCV co-infection. Pregnancy, 
nevirapine-based regimen and baseline CD4 $>250$ cells $/ \mathrm{mm}^{3}$ were not associated with liver enzyme elevation (Aaron et al., 2010).

Furthermore, a retrospective analysis of registries of HIV- infected pregnant women assisted at Helios Solud Buenos Aires, Argentina (1997-2006) was performed. It was observed that incidence of hepatotoxicity, was low (Cecchini et al., 2011). Similar observation were also been reported by other investigators (Thomas et al., 2005; Natarajan et al., 2007). In a retrospective analysis of 879 participants (533 men, 346 women 119 pregnant women) with median CD4 cell count of 212 in men and 231 in women. All the 879 participants were exposed to nevirapine, hepatoxicity was observed to occurred in $4.9 \%$ of the women and $3.5 \%$ of the men, no association was found with either pregnancy or CD4 cell count and hepatotoxicity (Bottaro et al., 2010).

A prospective cohort study was conducted in Abijan, Coted'ivoire between August 2003 and October 2006. In this study 530 women who enrolled in MTCT-plus were used and 290 women were on nevirapine containing regimen. Results from this work showed that CD4 and pregnancy are not risk factors associated with nevirapine associated hepatotoxicity (Coffie et al., 2010). Another study was carried out to assess the risk of nevirapine containing HAART-induced hepatotoxicity in pregnant Thai women with CD4 count of $250-350$ cells $/ \mathrm{mm}^{3}$. Moderate and mild (grade I-II) hepatotoxicity, asymptomatic hepatotoxicity and grade III-IV rash were more frequent in pregnant women with CD4 counts $>350$ cells $/ \mathrm{mm}^{3}$; the study did not report any severe hepatotoxicity. Overall, the study did not find any significant association between toxicity and CD4 counts of 250-350 cells $/ \mathrm{mm}^{3}$ (Phanuph, 2007). There was on relationship found between liver enzyme elevation, nevirapine therapy and pregnancy but pregnancy was found to be associated with liver enzyme elevation in HIV (Ouyang et al., 2009).

It was observed that pregnancy does not alter the pharmacokinetics parameter of nevirapine. One of these studies was performed to determine the impact of pregnancy on the pharmacokinetics of nevirapine in twenty-six pregnant women. Inference showed that pregnant does not alter nevirapine pharmacokinetics (Capparelli et al., 2008). In two open-label Pediatric AIDS Clinical Trials Group Studies (P1022 and P1026S), each participants was administered 200mg of nevirapine every $12 \mathrm{~h}$. Pharmacokinetics evaluations were performed during the second and the third trimester. These evaluations were repeated post partum. It was observed that the pharmacokinetics parameter of nevirapine was not altered.

\subsection{Genetics}

Researchers have reported the probability of genetic predisposition as a risk factor for nevirapine hypersensitivity (hepatotoxicity). Martin et al. (2005), in a retrospective study of 241caucasians for the correlation between genetic or immunological factors and nevirapine hypersensitivity, identified 26 cases of various types or allergic reactions to nevirapine of which 9 were hepatitis. When all hypersensitivity reactions were considered there was significant association between adverse reaction to nevirapine and the presence of HLA-DRBI*0101( $\mathrm{p}=0.014)$ (Martin et al., 2005).

Another study by Littera et al. (2006) exhibited the likely hood of genetic susceptibility as a predisposing factor to nevirapine hypersensitivity reaction. They studied 49 Sardinians HIV infected patients treated with nevirapine containing regimens, 13 patients $(26 \%)$ were victim of nevirapine hypersensitivity reaction. Further analysis of the 49 people and 82 HIV-infected patients not treated with nevirapine showed that $46 \%$ of those who experienced nevirapine hypersensitivity had two specific types of HIA markers (HLA-CW8 and HLA-B14).

Furthermore Gatnaga et al. (2007) studied 326 HIV-infected individuals (309 were Japanese) for correlation between HLA and drug induced adverse events. Forty one patients on nevirapine were divided into two groups; a nevirapine hypersensitivity group and a nevirapine tolerant group. Nevirapine hypersensitive group had 11 patients who experienced skin rash and one patient who developed nevirapine induced hepatotoxicity. The nevirapine tolerate group contained 29 people treated with nevirapine without hypersensitive reaction. In the nevirapine hypersensitive group 4 patients had HLA-CW*08DI and HLA-CW*0803. In the nevirapine tolerant group 3 patients had HLA-CW*0801, they concluded that their observation is in agreement with other reports (Littera et al., 2006; Gatnaga et al., 2007).

Differences in incidence of toxicity (hepatotoxicity) due to nevirapine may be associated with inherited genetic material as seen in Human Leukocyte Antigen (HLA) system. HLA are molecules on the surface of cells that are involved in immune recognition and allergies. The frequency of different HLA haplotypes varies in different populations and may affect diseases susceptibility (Tian et al., 2003). 


\section{CONCLUSION}

In this review it was observed that hepatitis $\mathrm{B}$ and $\mathrm{C}$ are risk factors for nevirapine hepatotoxicity in HIV positive patients. HIV positive patients should be screen for HCV or HBV and their liver function status should be known before administration of nevirapine containing regimens.HIV patients on nevirapine containing HAART should be monitored routinely for liver function. Due to discrepancies in reports correlation between nevirapine hepatotoxicity and gender, CD4 cell count and pregnancy need further evaluation. There are few reports that can buttress the involvement of genetic factor in nevirapine hepatotoxicity more evaluations are required to authenticate the involvement of genetic factor.

\section{REFERENCES}

Aaron, E., M.C. Kempf, S. Criniti, E. Tedaldi and E. Gracelt et al., 2010. Adverse events in a cohort of HIV infected pregnant and non-pregnant women treated with nevirapine versus non-nevirapine antiretroviral medication. PLOS, 9: 12617-12617.

Adaramoye, O.A., I.A. Adedara and E.O. Farombi, 2012. Possible ameliorative effects of kolaviron against reproductive toxicity in sub-lethally whole body gamma-irradiated rats. Exp. Toxicol. Pathol., 64: 379-85. PMID: 21036568

Adewale, B.D., D.J. Dumet, I. Vroh-Bi, O.B. Kehinde and D.K. Ojo et al., 2012. Morphological diversity analysis of African yam bean and prospects for utilization in germplasm conservation and breeding. Genet. Resources Crop Evolut., 59: 927-936. DOI: 10.1007/s10722-011-9734-1

Almond, L.M., M. Boffito, P.G. Hoggard, S. Bonora and R. Raiteri et al., 2004a. The relationship between nevirapine plasma concentrations and abnormal liver function tests. AIDS Res. Hum. Retroviruses, 20: 716-722. PMID: 15307917

Almond, L.M., M. Boffito, P.G. Hoggard, S. Bonora and R. Raiteri et al., 2004b. AIDS research and human. Retroviruses, 20: 716-722. PMID: 15307917

Antela, A., A. Ocampo, R. Gomez and M.J. Lopez et al. 2010. Liver toxicity after switching or simplifying to nevirapine-based therapy is not related to CD4 cell counts: Results of the TOSCANA study. HIV Clin. Trials, 11: 11-17.

Bacq, Y., O. Zarka and J.F. Brechot, 1996. Liver function tests in normal pregnancy: A prospective study of 103 pregnant women and 103 matched controls. Hepatology, 23: 1030-1034. PMID: 8621129
Baylor, M.S. and R. Johann-Liang, 2004. Hepatotoxicity associated with nevirapine use. J. Acquir. Immune. Defic. Syndr., 35: 538-539. PMID: 15021321

Bera, E., D. Naidoo and M. Williams, 2012. Maternal deaths following nevirapine-based antiretroviral therapy. Sout. Afr. J. HIV Med., 13: 196-197.

Bera, I. and R. Mia, 2012. Safety of nevirapine in HIVinfected pregnant women initiating antiretroviral therapy at higher CD4 counts: A systematic review and meta-analysis. South Afr. Med. J., 102: 855859. DOI: $10.7196 /$ samj.5700

Berenguer, J., J.M. Bellon, P. Miralles and E. Alvarez, 2008. Association between exposure to nevirapine and reduced liver fibrosis progression in patients with HIV and hepatitis $\mathrm{C}$ virus coinfection. Clin. Infect. Dis., 46: 137-143. DOI: 10.1086/524080

Bershoft-Matcha, S.J., L.M. Mundy and J.V. Henry, 2004. Nevirapine, pregnancy and adverse events. Proceedings of the 11th Conference on Retroviruses and Opportunistic Infections, Feb. 8-11, Moscone West, San Francisco, CA.

Black, V. and H. Rees, 2008. Incidence of nevirapineassociated hepatitis in an antenatal clinic. South Med. J., 98: 116-118. PMID: 18350206

Bonacini, M., 2004. Liver injury during highly active antiretroviral therapy: The effect of hepatitis C coinfection. Clin. Infect. Dis., 38: 104-108. DOI: $10.1086 / 381453$

Bonnet, F., S. Lawson-Ayayi, R. Thiebaut, R. Ramanampamonjy and D. Lacoste et al., 2002. A cohort study of nevirapine tolerance in clinical practice: French Aquitaine Cohort, 1997-1999. Clin. Infect. Dis., 35: 1231-1237. DOI: 10.1086/343046

Bottaro, E.G., M.J. Huberman, M.C. Iannella, F.A. Vesperoni and P.G. Scapellato et al., 2010. Nevirapine-associated toxicity in clinical practice in Buenos Aires, Argentina. J. Int. Assoc. Phys. AIDS Care, 9: 306-312. DOI: 10.1177/1545109710376250

Capparelli, E.V., F. Aweeka, J. Hitti, A. Stek and C. Hu et al., 2008. Chronic administration of nevirapine during pregnancy: Impact of pregnancy on pharmacokinetics. HIV Med., 9: 214-220. DOI: 10.1111/j.1468-1293.2008.00553.x

Carr, A. and D.A. Cooper, 2000. Adverse effects of antiretroviral therapy. Lancet, 356: 1423-1430. DOI: 10.1016/S0140-6736(00)02854-3

Cecchini, D., A. Uruena, P. Trinidad, F. Vespersoni and D. Mecikovsky, 2011. HIV and pregnancy: Maternal and neonatal evolution. Med. (Buonos Alres), 71: 432-436. PMID: 22057168 
Chng, C.L., M. Morgan, I. Hainsworth and J.G.C. Kingham, 2002. Prospective study of liver dysfunction in pregnancy in Southwest Wales. Gut, 51: 876-880. DOI: 10.1136/gut.51.6.876

Coca, N.S., M.S. Oliveira, I. Voieta, C.M. Antunes and J.R. Lambertucci, 2010. Antituberculosis druginduced hepatotoxicity: A comparison between patients with and without human immunodeficiency virus seropositivity. Rev. Soc. Bras. Med. Trop., 43: 624-628. DOI: 10.1590/S0037-86822010000600004

Coffie, P., B.A. Tonwe-Gold, K. Tanon and C. Amiani. 2010. Incidence and risk factors of severe adverse events with nevirapine-based antiretroviral therapy in HIV-infected women. MTCT-Plus program, Abidjan, Côte d'Ivoire. BMC Infect. Dis., 10: 1-10. PMID: 20576111

Dieterich, T.D., A.P. Robison, J. Love and O.J. Stern, 2004. Drug-induced liver injury associated with the use of nonnucleoside reverse-transcriptase inhibitors. Clin. Infect. Dis., 38: 508-509. PMID: 14986279

Edwards, S.G, N. Larbalestier, P. Hay, D. Ruiter and J. Welch et al., 2001b. Experience of nevirapine use in a London cohort of HIV-infected pregnant women. HIV Med., 2: 89-91. DOI: 10.1046/j.14681293.2001.00059.x

Edwards, S.G., N. Larbalestier, P. Hay, D. Ruiter and J. Welch et al., 2001a. Experience of nevirapine use in a London cohort of HIV-infected pregnant women. HIV Med., 2: 89-91. DOI: 10.1046/j.14681293.2001.00059.x

Fagot, J.P., M. Mockenhaupt, J.N. Bouwes-Bavnick, L. Naldi and C. Viboud et al., 2001. Nevirapine and the risk of Stevens-Johnson syndrome or toxic epidermal necrolysis. AIDS, 15: 1843-1848. PMID: 11579247

Friis-Moller, N., R. Weber, A.D. Monforte, W. El-Sadr and P. Reiss et al., 2003b. Exposure to HAART is associated with an increased risk of myocardial infarction: The D: A: D study. Proceedings of the 10th Conference on Retroviruses and Opportunistic Infections, Feb. 10-14, Boston, Mass.

Friis-Moller, N., R. Weber, P. Reiss, R. Thièbaut and O. Kirk et al., 2003a. DAD study group. Cardiovascular disease risk factors in HIV patientsassociation with antiretroviral thrapy: Results from the DAD study. AIDS, 17: 1179-1193. DOI: 10.1097/00002030-200305230-00010
Fuping, G., L. Wei, H. Yang, Q. Zhifeng and Z. Lingyan et al., 2010. Impact of hepatitis $C$ virus coinfection on HAART in HIV-infected individuals: Multicentric observation cohort. J. Acquir. Immun. Defic. Syndr., 54: 137-142. DOI: 10.1097/QAI.0b013e3181cc5964

Gatnaga, H., H. Yazaki, J. Tanuma, M. Honda and I. Genka et al., 2007. HLA-Cw8 primarily associated with hypersensitivity to nevirapine. AIDS, 21: 264265. DOI: 10.1097/QAD.0b013e32801199d9

Harris, M. and J.S. Montaner, 2000. Clinical uses of nonnucleoside reverse transcriptase inhibitors. Rev. Med. Virol., 10: 217-229. PMID: 10891870

Heil, E.L., M.L. Townsend, K. Shipp and A. Clarke, 2010. Incidence of severe hepatotoxicity related to antiretroviral therapy in $\mathrm{HIV} / \mathrm{HCV}$ coinfected patients. AIDS Res. Treat., 1: 1-4. DOI: 10.1155/2010/856542

Herlitz, L.C., S. Mohan, M.B. Stokes, J. Radhakrishnan and V.D. D'Agati et al., 2010. Tenofovir nephrotoxicity: Acute tubular necrosis with distinctive clinical, pathological and mitochondrial abnormalities. Kidney Int., 78: 1171-1177. DOI: 10.1038/ki.2010.318

Hitti, J., L. Frenkel, A. Stek, S. Nachman and A. Gonzalez-Garcia et al., 2004. Maternal toxicity with continuous nevirapine in pregnancy: Results from PACTG 1022. J. Acquir. Immun. Defic. Syndr., 36: 772-776. PMID: 15213559

Jamisse, L., J. Balkus, J. Hitti, S. Gloyd and R. Manuel et al., 2007. Antiretroviral-associated toxicity among HIV-1-seropositive pregnant women in Mozambique receiving nevirapine-based regimens. J. Aquir. Immun. Defficiency Synd., 1: 371-376. PMID: 17259905

Joao, E.C., G.A. Calvet, J.A. Menezes, M.L. Cruz and L.A. Salgado et al., 2006. Nevirapine toxicity in a cohort of HIV-1-infected pregnant women. Am. J. Obstet. Gynecol., 194: 199-202. PMID: 16389032

Knobel, H., J.M. Miro, B. Mahillo, A. Rivero and E. Ribera et al., 2004. Failure of cetirizine to prevent nevirapine-associated rash: A double-blind placebocontrolled trial for the GESIDA 26/01 Study. J. AIDS, 37: 1276-1281. PMID: 15385735

Kondo, W., A.A. Astori, S.K. Gomes, R.B. Fernandes and M. Sasaki et al., 2008 Evaluation of the adverse effects of nevirapine in HIV-infected pregnant women in a South Brazilian University Hospital. Rev. Bras. Ginecol. Obstet., 30: 19-24. PMID: 19142538 
Kondo, W., E.A. Carraro, E. Prandel, J.M. Dias and J. Perini, 2007. Nevirapine-induced side effects in pregnant women: Experience of a Brazilian university hospital. Braz. J. Infect. Dis., 11: 544548. DOI: 10.1590/S1413-86702007000600004

Kramer, F., A. Stek, G. Sheehan, C. Bergin and F. Mulcahy, 2004. Nevirapine tolerability in HIV infected women in pregnancy-a word of caution.

Labarga, P., V. Soriano, M.E. Vispo, J. Pinilla and L. Martin-Carbonero et al., 2007. Hepatotoxicity of antiretroviral drugs is reduced after successful treatment of chronic hepatitis $\mathrm{C}$ in HIV-infected patients. J. Infect. Dis., 196: 670-676. PMID: 17674307

Langlet, P., M.P. Guillaume, J. Devriendt D. Vokaer and L. Deltenre et al., 2000. Fatal liver failure associated with nevirapine in a pregnant HIV patient: The first reported case. Gastroenterology, 118: A1461A1461. DOI: 10.1016/S0016-5085(00)81744-8

Law, W.P., G.J. Dore, C.J. Duncombe, A. Mahanontharit and M.A. Boyd et al., 2003. Risk of severe hepatotoxicity associated with antiretroviral therapy in the HIVNAT Cohort, Thailand, 1996-2001. AIDS, 17: 2191-2199. DOI: 10.1097/00002030200310170-00007

Lazzari, D.E., A. Leon, J.A. Arnaiz, E. Negredo and B. Clotet et al., 2008. Hepatotoxicity of nevirapine in virologically suppressed patients according to gender and CD4 cell counts. HIV Med., 9: 221-226. DOI: $10.1111 / \mathrm{j} .1468-1293.2008 .00552 . \mathrm{x}$

Leth, V.F., S. Andrews, B. Grinsztein, M.K. Lazanas and J.M. Lange et al., 2005. The effect of baseline CD4 cell count and HIV-1 viral load on the efficacy and safety of nevirapine or efavirenz-based first-line HAART. AIDS, 19: 463-471. PMID: 15764851

Littera, R., R. Littera, C. Carcassi, A. Masala and P. Piano et al., 2006. HLA-dependent hypersensitivity to nevirapine in Sardinian HIV patients. AIDS, 20: 1621-1626. PMID: 16868443

Lyons, F., S. Hopkins, B. Kelleher, A. McGeary and G. Sheehan, 2006. Maternal hepatotoxicity with nevirapine as part of combination antiretroviral therapy in pregnancy. HIV Med., 7: 255-260. DOI: 10.1111/j.1468-1293.2006.00369.x

Macias, J., V. Castellano, N. Merchante, J.A. Mira and F. Lozano et al., 2004. Effect of antiretroviral drugs on liver fibrosis in HIV-infected patients with chronic hepatitis $\mathrm{C}$ : harmful impact of nevirapine. AIDS, 18: 767-774. PMID: 15075511
Magiolo, F., C. Arici, M. Alriodi, D. Ripamonti and G. Quinzan et al., 2007. Reasons for discontinuation of nevirapine-containing HAART: Results from an unselected population of a large clinical cohort. J. Antimicrob. Chemother., 59: 569-572. PMID: 17255141

Manfredi, R. and L. Calza, 2006. Nevirapine versus efavirenz in 742 patients: No link of liver toxicity with female sex and a baseline CD4 cell count greater than 250 cells/mL. AIDS, 20: 2233-2236. PMID: 17086066

Manosuthi, W., C. Athichathanabadi, S. Uttayamakul, T. Phoorisri and S. Sungkanuparph, 2007. Plasma nevirapine levels, adverse events and efficacy of antiretroviral therapy among HIV-infected patients concurrently receiving nevirapine-based antiretroviral therapy and fluconazole. BMC Infect. Dis., 7: 14-14. DOI: 10.1186/1471-2334-7-14

Marazzi, M.C., P. Germano, G. Liotta, G. Guidotti and S. Loureiro et al., 2006. Safety of nevirapinecontaining antiretroviral triple therapy regimens to prevent vertical transmission in an African cohort of HIV-1-infected pregnant women. HIV Med., 7: 338344. PMID: 16945080

Martin, A., D. Nolan, I. James, P. Cameron and J. Keller et al., 2005. Predisposition to nevirapine hypersensitivity associated with HLA-DRB1_0101 and abrogated by low CD4+ T cell counts. AIDS, 19: 97-99. PMID: 15627041

Mbougua, J.B., C. Laurent, C. Kouanfack, A. Bourgeois and L. Ciaffi et al., 2010. Hepatotoxicity and effectiveness of a Nevirapine-based antiretroviral therapy in HIV-infected patients with or without viral hepatitis $\mathrm{B}$ or $\mathrm{C}$ infection in Cameroon. BMC Public Health, 10: 105-105. PMID: 20193053

McKoy, J.M., C.L. Bennett, M.H. Scheetz, V. Differding and K.K. Scarsi et al., 2009. Hepatotoxicity associated with long versus shoot-course HIV prophylactic Nevirapine use. Drug. Saf., 32: 147158. DOI: 10.2165/00002018-200932020-00007

Medrano, J., P. Bairrero, P. Tuma, E. Vispo and P. Labarga et al., 2008. Risk for immune-mediated liver reactions by nevirapine revisited. AIDS Rev., 10: 110-115. PMID: 18615121

Mocroft, A., S. Staszewski, R. Weber, J. Gasiorowski and G. Panos et al., 2007. Risk of discontinuation of nevirapine due to toxicities in antiretroviral-naive and -experienced HIV-infected patients with high and low CD4+ T-cell counts. Antiviral Ther., 12: 325-333. PMID: 17591022 
Murphy, R. and J. Montaner, 1996. Nevirapine: A review of its development, pharmacological profile and potential for clinical use. Exp. Opin. Invest. Drugs, $\quad$ 5: 1183-1199. DOI: 10.1517/13543784.5.9.1183

Nagu, T.J., M. Kanyangarara, C. Hawkins, E. Hertmark and G. Chalamila et al., 2012. Elevated alanine aminotransferase in antiretroviral-naïve HIVinfected African patients: Magnitude and risk factors. HIV Med., 13: 541-548. DOI: 10.1111/j.1468-1293.2012.01006.x

Natarajan, U., A. Pym, C. McDonald, S.G. Edwards and P. Hay et al., 2007. Safety of nevirapine in pregnancy. HIV Med., 8: 64-69. DOI: 10.1111/j.1468-1293.2007.00433.x

Ocama, P., M. Katwere, T. Piloya, J. Feld and K.C. Opio et al., 2008. The spectrum of liver diseases in HIV infected individuals at an HIV treatment clinic in Kampala, Uganda. Afr. Health Sci., 8: 8-12. PMID: 19357726

Ofotokun, I., S.E. Smithson, C. Lu, K.A. Easley and J.L. Lennox, 2007. Liver enzymes elevation and immune reconstitution among treatment-naïve HIV-infected patients instituting antiretroviral therapy. Am. J. Med. Sci., 334: 334-341. DOI: 10.1097/MAJ.0b013e31811ec780

Ouyang, D.W., D.E. Shapiro, M. Lu, S.B. Brogly and A.L. French et al., 2009. Increased risk of hepatotoxicity in HIV-infected pregnant women receiving antiretroviral therapy independent of nevirapine exposure. AIDS, 27: 2425-2430. PMID: 19617813

Peter, J.P., N. Polle, C. Zeh, R. Masabra and B. Oyaro et al. 2011. Nevirapine-associated hepatotoxicity and rash among HIV-infected pregnant women in Kenya. J. Int. Assoc. Phys. AIDS Care, 111: 142149. DOI: $10.1177 / 1545109711423445$

Peters, P.J., J. Stringer, M.S. McConnell, W. Ratanasuwan and P. Intalapaporn et al., 2010. Nevirapine-associated hepatotoxicity was not predicted by $\mathrm{CD} 4$ count $\geq 250$ cells $/ \mu \mathrm{L}$ among women in Zambia, Thailand and Kenya. HIV Med., 11: $\quad 650-660$. DOI: $\quad 10.1111 / \mathrm{j} .1468-$ 1293.2010.00873.x

Phanuph, N., 2007. Toxicities from Nevirapine (NVP)based antiretroviral regimens in pregnant women with CD4 count between 250-350 cells $/ \mathrm{mm} 3$. Proceedings of the 14th Conference on Retroviruses and Opportunistic Infections, Feb. 25-28, Los Angeles, USA.
Phillips, E., S. Gutierrez and N. Jahnke, 2007. Determinants of nevirapine hypersensitivity and its effect on the association between hepatitis $\mathrm{C}$ status and mortality in antiretroviral drugnaive HIVpositive patients. AIDS, 21: 1561-1568. DOI: 10.1097/QAD.0b013e3282170a9d

Pilliero, P.J. and B. Purdy, 2001. Nevirapine-induced hepatitis: A case series and review of the literature. AIDS Read., 11: 379-382. PMID: 11494710

Pineda, J.A. and J. Macias, 2005. Progression of liver fibrosis in patients coinfected with hepatitis $C$ virus and human immunodeficiency virus undergoing antiretroviral therapy. J. Antimicrob. Chemot., 55: 417-419. DOI: $10.1093 / \mathrm{jac} / \mathrm{dkh} 555$

Prakash, M., V. Poreddy, L. Tiyyagura and M. Bonacini, 2001. Jaundice and hepatocellular damage associated with nevirapine therapy. Am. J. Gastroenterol., 96: 1571-1573. PMID: 11374701

Saint-Marc, T., M. Partisani, I. Poizot-Martin, F. Bruno and O. Rouviere et al., 1999. A syndrome of peripheral fat wasting (lipodystrophy) in patients receiving long-term nucleoside analogue therapy. AIDS, 13: 1359-1367. PMID: 10509567

Snijdewind, I.J., C. Smit, H.M. Godfried, J.F. Nellen and K. Boer et al., 2012. Hcv coinfection, an important risk factor for hepatotoxicity in pregnant women starting antiretroviral therapy. J. Infect., 64: 409416. DOI: $10.1016 /$ j.jinf.2011.12.012

Stern, J.O., P.A. Robinson, J. Love, S. Lanes and M.S. Imperiale et al., 2003. A comprehensive hepatic safety analysis of nevirapine in different populations of HIV infected patients. J. Acquir. Immun. Defic. Syndr., 34: 21-33. DOI: 10.1097/00126334200309011-00005

Storfer, S., J. Leith, P. Robinson, P. Piliero and D. Hall, 2005. Analysis of hepatic events within the $2 \mathrm{NN}$ study: Controlling for geographic region and CD4+ cell count at initiation of nevirapine therapy. Eur. AIDS Clin. Soc., 6: 254-261.

Sulkowski, M.S., D.L. Thomas, S.H. Mehta, R.E. Chaisson and R.D. Moore, 2002. Hepatotoxicity associated with nevirapine or efavirenz-containing antiretroviral therapy: Role of hepatitis C and B infections. Hepatology, 35: 182-189. DOI: 10.1053/jhep.2002.30319

Thomas, T., P. Amornkul, J. Mwidau, R. Masaba and L. Slutsker et al., 2005. Preliminary findings: Incidence of serious adverse events attributed to nevirapine among women enrolled in an ongoing trial using HAART to prevent mother-to-child HIV transmission. Proceedings of the 12th Conference on Retroviruses and Opportunistic Infections, Feb. 2225, Boston, MA, USA. 
Tian, W., D.A. Boggs, G. Uko, B. Banjoko and T. Adewole et al., 2003. MICA, HLA-B haplotypic variation in five population groups of sub-Saharan African ancestry. Genes. Immunity, 4: 500-505. PMID: 14551603

Torty, C., S. Costaralle, A. Desilvestri, E. QuirosRoldom and G. Lapadula et al., 2007. Analysis of severe hepatic events associated with nevirapinecontaining regimens: CD4+ T-cell count and gender in hepatitis $\mathrm{C}$ seropositive and seronegative patients. Drug Safety, 30: 1161-1169. PMID: 18035868

Umar, R.A., S.W. Horsan, M.J. Ladan and I.K. Matazu, 2008. Adverse hepatic effects associated with administration of antiretroviral drugs (nevinaprine, lamivudine and stavudine to albino rat; implication for management of patient with HIV/AIDS. A. J. Biochem., 3: 19-25.

Vogel, M., N. Bertram, J.C. Wasmuth, C. Wyen and E. Voigt et al., 2009. Nevirapine pharmacokinetics in HIV-infected and HIV/HCV-coinfected individuals. J. Antimicrob. Chemother., 63: 988-991. PMID: 19270314
Wang, J., H. Kou, Q. Fu, Y. Han and Z. Qiu et al., 2011. Nevirapine plasma concentrations are associated with virologic response and hepatotoxicity in chinese patients with HIV infection. PLoS ONE, 6: 26739-26739.

Weidle, P.J., D. Moore, J. Mermin, R. Downing and A. Kigozi et al., 2008. Liver enzymes improve over twenty-four months of first-line non-nucleoside reverse transcriptase inhibitor-based therapy in rural Uganda. AIDS Patient Care STDS, 22: 787-795. PMID: 18778241

Wolf, E., C. Koegl and T. Theobald, 2006. Nevirapineassociated hepatotoxicity: No increased risk for females or high CD4 count in a single centre HIV cohort. Proceedings of the Program and Abstracts of the 46th ICAAC, Sept. 27-30, San Francisco, CA. 